\title{
Study on The Regeneration Performance of Reclamation of The Used Sands Vane Wheel Equipment
}

\author{
Wenlong $\mathrm{Lu}^{1, \mathrm{a}}$, Shan $\mathrm{Li}^{2, \mathrm{~b}}$ and Qiang Chen ${ }^{3, \mathrm{c}}$ \\ ${ }^{1}$ Mechanical and Electrical Engineering College, Kunming University of Science and Technology, \\ kunming, China \\ ${ }^{2}$ Mechanical and Electrical Engineering College, Kunming University of Science and Technology, \\ kunming, China \\ ${ }^{3}$ Mechanical and Electrical Engineering College, Kunming University of Science and Technology, \\ kunming, China \\ aluwlchn@163.com, b24814911@qq.com, ${ }^{\circ} 544280704 @ q q . c o m$
}

Keywords: Reclamation of the used sand, Wheel machine, Vane

Abstract. This paper expounds that the significance of the regeneration of the used sand, design structure, working principle, working mode and advantages of reclamation of vane wheel equipment. The test prototype of reclamation of vane wheel equipment was used to reclaim the used sand, and the clay content of the used sand was measured. The regeneration ability of reclamation of vane wheel equipment was analyzed by the test data.

\section{Introduction}

Foundry industry is the basic industry of automobile, petrochemical, iron and steel, electric power, shipbuilding, textile, equipment manufacturing and other pillar industries. In 2008, China's total output of casting 33.5 million tons, which is equivalent to the sum of the United States, Japan, India and Germany casting production that the four countries ranked 2 to 5 in global casting production [1]. In the casting process, China's annual use new sand about 30 million tons, and the amount of the used sand thrown away is very considerable. Quartz sand is a finite resource. This is not only a huge waste of natural resources bust also a kind of pollution to our environment. Currently, in abroad, clay content can be reduced to $1 \%$ to $2 \%$ after the used sand reclaiming. But China is still not up to the standard, and the production efficiency is not high. The used sand reclaiming can reduce the production cost and environmental pollution and save natural resources, and so there is a great significance to sustainable development of the foundry industry.

\section{Significance of The he Used Sand Reclaiming}

Reduce Costs. First of all, the cost of molding sand is the most important factor influencing the Casting costs. The reclamation sand can take the place of new sand to decrease the number of use. Second, with the reclamation sand enabled, adhesives usage is substantially reduced. Finally, the reclamation sand help our save some expenditures. Such as, new sand and the used sand transportation costs, the used sand disposal fees and so on.

Protection of The Environment. According to 2008 statistics, China's annual used sand caused about more than 30 million tons, now there is still an increasing trend in the casting production of our country. However, the general the used sand were processed that can be recycled $75 \% \sim 90 \%$. That is to say, the use of new sand is relatively reduced, meanwhile reducing the pollution.

Improve the Quality of Casting. After the reclamation of the used sand, uniform size distribution, flowing ability is good and bring the casting defects. For the used sand reclaiming machine using friction principle, sand reclaiming process is achieved by rubbing against each other. Sand surface is so smooth to reduce the use of adhesives. Due to the thermal stability of the reclaimed sand is good, gas hole caused defects is easy to avoid in the process of casting, thereby improving the performance of molding sand, the density and strength of filling, to improve the liquidity of molding sand. Finally, it can improve the accuracy of castings and improve the surface quality of castings. 


\section{Design of Reclamation of Vane Wheel Equipment}

Reclamation of vane wheel Equipment overall structure diagram was shown in Fig. 1. The A-A sectional drawing shown in Fig. 2.

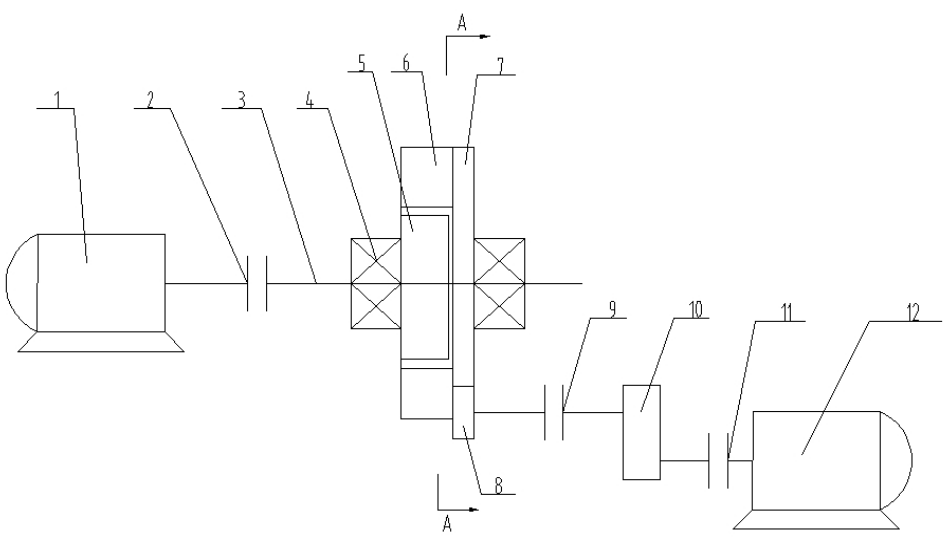

Fig. 1 Reclamation of equipment structure diagram

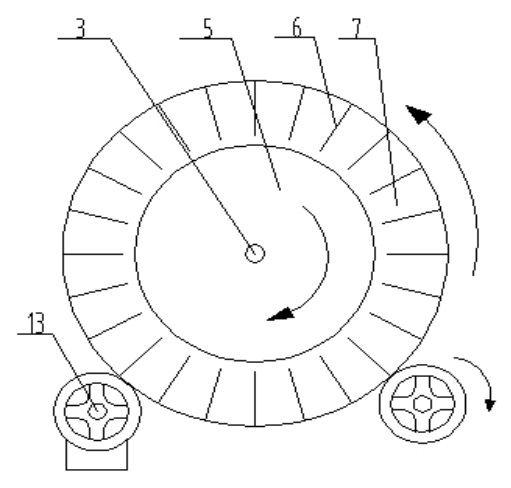

Fig.2 The A-A sectional drawing

Marked in the fig. 1 and fig. 2 the label represents the name of parts is as follows: 1 the grinding wheel electromotor, 2 the coupling, 3 the spindle, 4 the bearing, 5 the grinding wheels, 6 the vanes, 7 the roller, 8 the driving wheel, 9 the low speed coupling, 10 the retarder, 11 the high speed coupling, 12 the roller electromotor, 13 the supporting wheel.

The grinding wheel electromotor $\langle 1\rangle$ is connected with the spindle $\langle 3\rangle$ by the coupling $\langle 2\rangle$. Grinding wheels $\langle 5\rangle$ is fixed on the spindle $\langle 3\rangle$ and the spindle $\langle 3\rangle$ is arranged in the bearing $\langle 4\rangle$. The roller electromotor $\langle 12\rangle$ is connected with the retarder $\langle 10\rangle$ by the high speed coupling $\langle 11\rangle$, the output shaft of the reducer $\langle 10\rangle$ is connected with the driving wheel $\langle 8\rangle$ by the low speed coupling $\langle 9\rangle$, the driving wheel $\langle 8\rangle$ is arranged at the bottom left of the roller $\langle 7\rangle$, and is contact with the outer end ring of the roller $\langle 7\rangle$. The supporting wheel $\langle 13\rangle$ is mounted on the other side of the roller $<7>$ to balance. In the used sand reclaiming process, the equipment actuated the grinding wheel electromotor $\langle 1\rangle$ and the roller electromotor $\langle 12\rangle$. Regarding the grinding wheel electromotor $\langle 1\rangle$ as motive force, transmit to the grinding wheels $\langle 5\rangle$ through the coupling $\langle 2\rangle$ to rotate the grinding wheel $\langle 5\rangle$ at high speed. The rotary electromotor $\langle 12\rangle$ through the high speed coupling $\langle 11\rangle$, the retarder $\langle 10\rangle$ and the low speed coupling $\langle 9\rangle$ driven the driving wheel $\langle 8\rangle$ at low speed, the driving wheel $\langle 8\rangle$ through the friction end ring of the roller $\langle 7\rangle$ drive the roller $\langle 7\rangle$ low speed rotation, the friction end ring of the roller $\langle 7\rangle$ also drives the supporting wheel $\langle 13\rangle$ to rotate freely. The casting used sand is elevated to the height under the action of the vanes $\langle 6\rangle$ in the roller $\langle 7\rangle$. Due to grinding wheels $\langle 5\rangle$ and the roller $\langle 7\rangle$ has difference rotational speed. The three-cornered interaction among sand, grinding wheels $\langle 5\rangle$ and the vane $\langle 6\rangle$ are gotten shock, friction and press under the action of speed difference in the sand falling from height to grind the surface of the casting used sand, covering the surface of the used sand with resin, inert film bonding and sticky materials was removed. This is the casting used sand for regeneration.

\section{Experimental Result}

The correspond relationship between sand fineness factor and sieve number is shown in Table 1 .

Table 1 Sand fineness factor

\begin{tabular}{lccccccccc}
\hline $\begin{array}{l}\text { sieve } \\
\text { number }\end{array}$ & 30 & 40 & 50 & 70 & 100 & 140 & 200 & 270 & $\begin{array}{l}\text { pan } \\
\text { bottom }\end{array}$ \\
\hline $\begin{array}{l}\text { fineness } \\
\text { factor }\end{array}$ & 20 & 30 & 40 & 50 & 70 & 100 & 140 & 200 & 300 \\
\hline
\end{tabular}

The computational formula of average particle size is:

$$
\eta=\frac{\sum p_{n} x_{n}}{\sum p_{n}}
$$


In above formula, nis for the average fineness of reclaimed sand, $p_{n}$ as a percentage of the total amount of recycled sand on any sieve number, $x_{n}$ for fineness factor, $n$ as the screen size [2].

The distance between the vane and the grinding wheel, the wheel linear velocity and process time as test of the adjustment three parameters, the number of vane is fixed to 24 , a total of 36 trials. In this experiment, using" the wheel linear velocity -- process time-- the distance between the vane and the grinding wheel" simplified representation as a serial number for each test. For example,"19-20--1" means: the wheel linear velocity $=3 \mathrm{~m} / \mathrm{s}$; process time $=20 \mathrm{~min}$; the distance between the vane and the grinding wheel $=1 \mathrm{~mm}$. The results of the test are shown in Table 2 to Table 4 .

Table 2 Test results of the distance of $1 \mathrm{~mm}$

\begin{tabular}{lll}
\hline Test number & The clay content $(\%)$ & The average fineness \\
\hline $19-20-1$ & 4.4 & 60 \\
$19-15-1$ & 5.6 & 59 \\
$19-10-1$ & 6 & 56 \\
$19-5-1$ & 8 & 54 \\
$17-20-1$ & 5 & 59 \\
$17-15-1$ & 5.4 & 58 \\
$17-10-1$ & 6.6 & 56 \\
$17-5-1$ & 7.8 & 54 \\
$15-20-1$ & 4.8 & 58 \\
$15-15-1$ & 6.2 & 56 \\
$15-10-1$ & 7.8 & 53 \\
$15-5-1$ & 8.4 & 51 \\
\hline
\end{tabular}

Table 3 Test results of the distance of $2 \mathrm{~mm}$

\begin{tabular}{lll}
\hline Test number & The clay content $(\%)$ & The average fineness \\
\hline $19-20-2$ & 6 & 58 \\
$19-15-2$ & 7.2 & 56 \\
$19-10-2$ & 7.6 & 55 \\
$19-5-2$ & 8.4 & 54 \\
$17-20-2$ & 6.6 & 58 \\
$17-15-2$ & 7.4 & 55 \\
$17-10-2$ & 7.8 & 54 \\
$17-5-2$ & 8.6 & 53 \\
$15-20-2$ & 7 & 57 \\
$15-15-2$ & 7.8 & 55 \\
$15-10-2$ & 8.2 & 53 \\
$15-5-2$ & 9.4 & 51 \\
\hline
\end{tabular}

Table 4 Test results of the distance of $3 \mathrm{~mm}$

\begin{tabular}{lll}
\hline Test number & The clay content $(\%)$ & The average fineness \\
\hline $19-20-3$ & 7 & 59 \\
$19-15-3$ & 7.8 & 57 \\
$19-10-3$ & 8.6 & 55 \\
$19-5-3$ & 9.8 & 54 \\
$17-20-3$ & 6.8 & 58 \\
$17-15-3$ & 7.6 & 55 \\
$17-10-3$ & 9.2 & 54 \\
$17-5-3$ & 10 & 52 \\
$15-20-3$ & 7 & 57 \\
$15-15-3$ & 8 & 55 \\
$15-10-3$ & 9 & 52 \\
$15-5-3$ & 10.2 & 50 \\
\hline
\end{tabular}




\section{Analysis of Experimental Results}

The Influence of The Processing Time to The Clay Content of The Reclaimed Sand. As can be seen from the table 2 to table 4, with the increase of processing time, the overall trend of the clay content of the reclaimed sand is decreased. Taking the speed of grinding wheel line as an example of $15 \mathrm{~m} / \mathrm{s}$, as shown in Fig 3, with the increase of processing time, the clay content of the reclaimed sand decreased rapidly, and then decreased slowly.

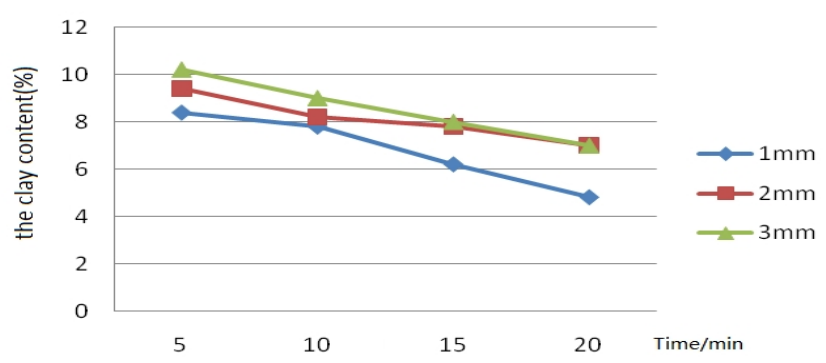

Fig 3 In the $15 \mathrm{~m} / \mathrm{s}$ case of the clay content

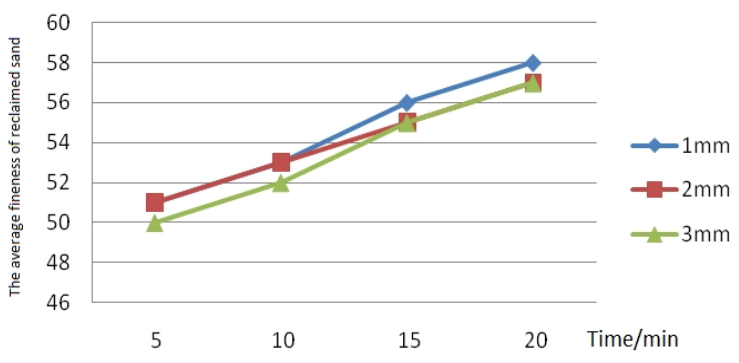

Fig 4 In the $15 \mathrm{~m} / \mathrm{s}$ case of fineness

The Influence of Processing Time to The Average Fineness of Reclaimed Sand. As can be seen from the table 2 to table 4, with the gap between the vanes and the grinding wheel increased, the average fineness increased significantly. Taking the speed of grinding wheel line as an example of $15 \mathrm{~m} / \mathrm{s}$, as shown in Fig 4, when the distance between the vanes and the grinding wheel is $2 \mathrm{~mm}$ and the $3 \mathrm{~mm}$, the curve is below the curve at the distance of $1 \mathrm{~mm}$. When the distance between the vanes and the grinding wheel is smaller, the Sand in the gap is more affected by the extrusion, so the high degree of refinement of sand.

The Influence of Linear Velocity to The Clay Content of The Reclaimed Sand. As can be seen from the table 2 to table 4, grinding wheel linear velocity had less effect on the clay content of the reclaimed sand. Duo to grinding wheel linear velocity of Clay membrane crushing was $16 \sim 18 \mathrm{~m} / \mathrm{s}$, but crushed quartz sand is more than the linear velocity of $23 \mathrm{~m} / \mathrm{s}$. So wheel speed should not exceed $23 \mathrm{~m} / \mathrm{s}$, not less than $15 \mathrm{~m} / \mathrm{s}$, taking $19 \mathrm{~m} / \mathrm{s}$ is about as appropriate.

The Influence of The Distance between The Vane and Grinding Wheel to The Clay Content of The Reclaimed Sand. As can be seen from the table 2 to table 4, with the distance between the vane and the grinding wheel increased, in the same circumstances, the clay content of the reclaimed sand is increased. So the distance between the vane and the grinding wheel is the most important factor to determine the regenerative effect of the regenerative machine, and the value of $1 \mathrm{~mm}$ is appropriate.

\section{Conclusions}

Reclamation of Vane Wheel Equipment should be used in the field of the reclaimed sand, in cleaner reclaimed machine and the eccentric wheel reclaimed machine based on innovation and research and design. Its used sand has good regeneration effect and stable performance.

\section{References}

[1]GUO Jing-chun, GUO si-fu, LI Shan, ZHANG Fang, CHEN Zu-yao, ZHU Shi-jun: Foundry Equipment and Technology. No.5, Oct. 2012. In Chinese.

[2] S.Fiore,M.C.Zanetti: International Journal Cast Metals Research,2008,21(6):435-438. 